\title{
Destruction in Niger
}

\author{
D. M. Jones
}

The author went to Niger in August-September 1972 to report and advise on the wildlife situation. This was as a result of a report by two residents, Mr and Mrs Barry Humphrey, describing the serious and continuing decline in Niger's wildlife, especially among the larger desert mammals, and the government's inability to raise the necessary money and manpower to protect it. In particular, poaching in the $W$ National Park in the south, and hunting mainly by Europeans in the Air Mountains in the north, where a large French mining company has concessions, are seriously depleting wildlife populations, notably addax and scimitar-horned oryx, both vulnerable species in the Red Data Book, and both desert-living species that can survive in the drought-ridden areas where cattle are dying and people starving. This article covers the gist of his report and recommendations.

Nine-tenths of Niger consists of desert (Saharan) and semi-arid (Sahelian) regions. The ecological balance of such regions is extremely fragile. Formerly the nomadic tribesmen and their livestock maintained a tenuous equilibrium with their environment, having little effect on the populations of large wild mammals and birds. But encroachment by vehicles and the dramatic population increase have disturbed this equilibrium. Now a series of exceptionally dry years, combined with the destructive grazing of increasing numbers of goats and camels, has resulted in a very serious drought, and there is famine in central West Africa.

\section{Mountains and Deserts}

The Air region, although the smallest of four mountain ranges in the central Sahara, covers an area the size of England, consisting mostly of low rocky hills with shallow, wide valleys. There are some deep wells, and in the wet season many valleys are relatively fertile, with groups of trees up to ten metres high in sheltered parts. The valley floors are either strewn with rocks or consist of low dunes supporting only hardy, coarse grasses. The desert surrounding this semi-arid region varies considerably. To the east is a vast waterless area of huge shifting sand dunes, the Erg du Tenère. To the south this gives way to smaller dunes between rocky outcrops, with higher rainfall, a permanent but thin grass covering, and a few small trees in the lowest areas. On the west and north sides of the range are rolling gravel and sand plains, with permanent coarse grasses in the lowest parts and also, after rain, the fast growing succulent grasses that are much favoured by the antelopes.

Addax Addax nasomaculatus favour the north of this region; the scimitar-horned oryx Oryx tao prefers the edges of the hills and the scrub areas in the south-east. Dorcas and dama gazelles Gazella 


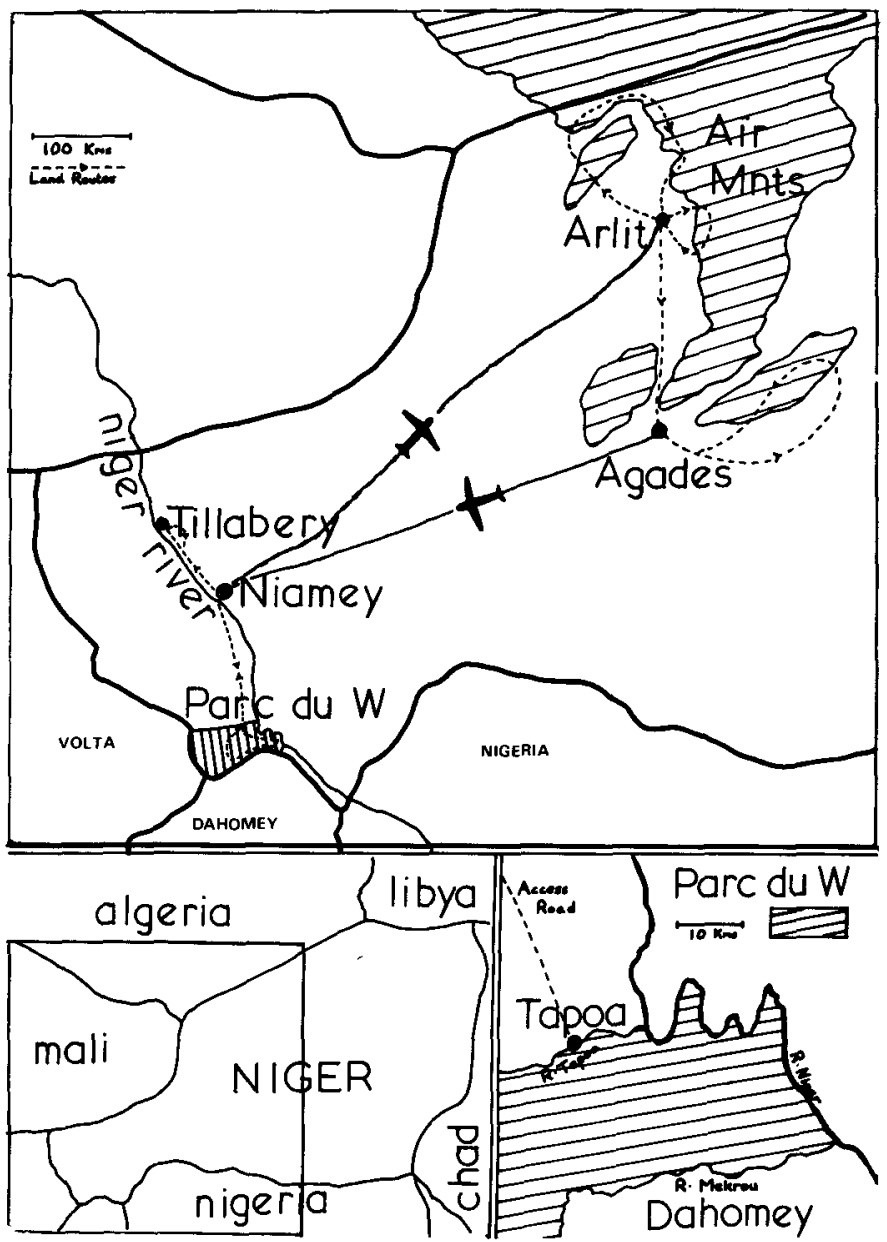

dorcas and $G$. dama are found throughout the region, the latter around the edges of the hills. Barbary sheep Ammotragus lervia, baboons Papio anubis, hyaenas Hyaena hyaena and cheetahs Acinonyx jubatus occur in the more central regions. But of all these, only the dorcas gazelle remains fairly common. According to the local Tuareg tribesmen, many of whom we questioned, there had been hunting on a vast scale from vehicles equipped for desert use in the last five years.

Three groups appear to be mainly responsible for the destruction of the wildlife in this region: military personnel, operating near the Algerian border, mining prospectors and engineers working in the Aïr, and a few local officials. The nomadic Tuaregs are unlikely to have a significant effect, but they are employed as guides and trackers. Hunting is now forbidden by law in Niger, but there is no machinery (because there is no money) to enforce the law. The 
Dorcas gazelle were widespread but not numerous. Small groups (2-8) consisting of both sexes were usually seen. On one occasion 16 were found running together. Three single very nervous dama gazelle and a pair of Loder's gazelle Gazella leptoceros were also recorded. At one watering place in the hills, we saw fresh tracks of an adult cheetah accompanied by a juvenile. Throughout the tour we were showing the staff from the Forest Department how to age and sex individual gazelles from a distance and to assess the reproductive potential of a group, and whenever possible we discussed these problems with the local governors, the French miners and agriculturalists. On the whole, these people could see the problems and the possible consequences, but there was relatively little concern and no evidence that any measures were being taken to try to solve the problems.

Further south, around Agades, however, the situation was even worse. Alongside the track running eastwards towards Bilma, the desert was littered with dead cattle and camels: stocks of both were almost totally wiped out last year. On the edge of the vast sand area of Tenère, 100 miles east of Agades, there are still a few remnant groups of scimitar-horned oryx, but in three days of searching we found none, although we crossed relatively fresh tracks on three occasions. A few single dama and small groups of dorcas gazelles were seen, and also ostriches Struthio camelus in small numbers.

The semi-arid Sahelian zone between the Aïr mountains and the savanna further south should have been relatively fertile at that time of year, but instead we saw large areas of dead and dying trees, and herds of goats, camels and cattle wandering about with very little to eat; the cultivated patches round the villages, where maize should have been six feet high, were almost barren. For years, Niger's most valuable commodity has been cattle which were sold further south in Nigeria. But the severe drought and the reduced demand during the Nigerian civil war have affected this trade severely, and in many areas it is now impossible to keep cattle. As a result goats and camels predominate, their numbers increasing to support the ever growing human population and compensate for the loss of cattle. Tree destruction accelerates to help feed these animals, leading to further soil erosion, and ultimately assisting the desiccation process.

In theory, if the wild ungulates were carefully protected and managed, they could, by virtue of their remarkable physiological adaptations, replace the domestic stock and be used to support the nomads' tenuous existence. But there are strong social and cultural bonds between the nomad and his livestock that will not be easily broken. The only nationals trained in ecology or agriculture occupy senior administrative positions where their training cannot be used in the field. There are virtually no experienced advisers from the developed countries whose subjects encompass these problems.

The Parc du W, Niger's only national park, delineated in 1948, lies on the south-western frontier with Dahomey and Upper Volta. The adjoining areas in these two latter countries are also supposed to be protected but it is doubtful whether this is so in practice. Only the Niger sector contains a reasonable track system, and the approach 
road from the capital Niamey, some 80 miles distant, is one of the best in the country. But lack of finance, both national and private, means that tourist facilities, equipment and staffing are minimal.*

The small area of Niger that is fertile for most of the year-less than a tenth-lies exclusively in the Niger River valley between the Mali and Nigerian frontiers. The park is bordered by the Niger river on the east, and by its seasonal tributaries, the Tapoa in the north and the Mekrou in the south, both with some spectacularly beautiful gorges. With these natural barriers the park would be relatively easy to protect with a small team of trained and well equipped men. The Forest Department, to their credit, have tried hard, and with some success, to stop the spread of villages into the park, but shortage of funds and trained manpower have resulted in the illegal grazing of cattle in the north-eastern sector and widespread poaching of ungulates everywhere, especially from the west side in the dry season. However, there are still viable, if depleted, populations of elephant Loxodonta africana, hippopotamus Hippopotamus amphibius, buffalo Syncerus caffer, roan Hippotragus equinus, bubal hartebeest Alcelaphus buselaphus, Buffon's kob Kobus kob, topi Damaliscus korrigum, reedbuck Redunca redunca, bushbuck Tragelaphus scriptus, red-flanked gazelle Gazella rufifrons, baboons Papio anubis and patas monkey Erythrocebus patas; the area is very rich in birds, and crocodile can easily be seen in all the rivers.

Two major threats hang over the park: first, there will be heavy pressures to use the land for grazing and cultivation as the government tries to find room for migrants moving in from the drought areas to the north; secondly, the large steel companies of at least two developed nations have already examined the potential of the rich iron ore deposits there that lie close to the surface.

\section{Girafies}

Generally speaking, the stocks of all large wild mammals in Niger have been reduced to a low level. The one species which is still locally numerous in certain places is the giraffe Giraffa camelopardalis, which inhabits a broad belt of the southern Sahelian zone from Tillabery on the Niger river, east to a point 50 miles south of Agades. In the former area, groups of from 10-30 are regularly seen, often browsing among herds of cattle and goats. Their survival is due to lack of competition for food at tree-top level and because the people do not often eat giraffe meat. But there has been considerable political pressure to reduce their numbers because of the damage they do to the maize fields on their way to find water. It would be worth trying to move some of these animals to areas where they were previously found, and, with this in mind, we instructed a number of senior field staff from the Water and Forest Department in the technique of capturing sub-adult giraffe using a projectile syringe and drugs. Because of their height and unusual cardiovascular physiology, giraffes are not easy to catch by this method, but the large number of erosion gullies and dried-up river beds made it impossible to catch fully conscious animals safely with

* An article on this park is on page 216. 


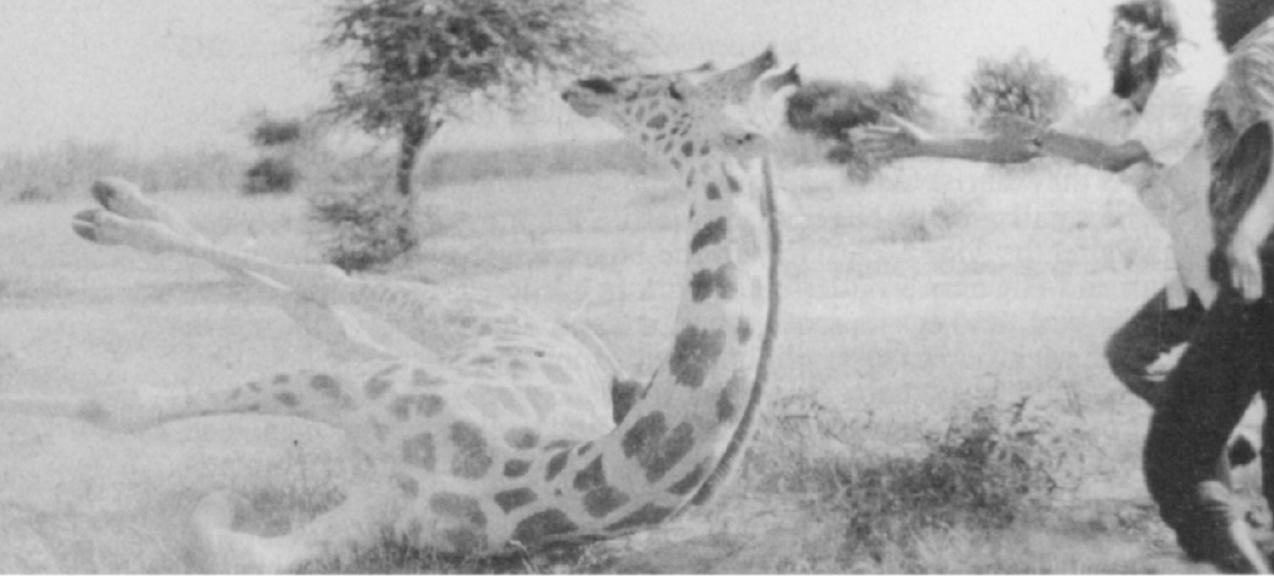

Above A drug-darted giraffe collapses on its knees and rolls on its side

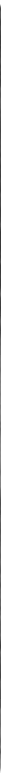

Above Three minutes after immobilisation

Below Thirty seconds after getting up, still mildly sedated and tractable

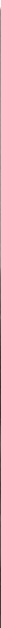


ropes from a moving vehicle. After a slow approach on foot, usually with the vehicle following at a distance, the animal was darted and a harness with ropes attached dropped over its head by a pole, which could then be used to guide it. On two occasions the animal collapsed prior to restraint with ropes, but when the neck and head were quickly held struggling subsided. The head was kept covered after the administration of the intravenous antidote, and physical restraint was maintained for from 1-14 minutes, until it was judged that the animal could rise quickly and safely. The animals remained tractable after getting up, and could easily have been guided into travelling crates.

Apart from the many other reasons, the woodland savannas of southern Niger must be preserved intact to protect the country's water supplies, but no developing nation could be blamed for looking into the present economics of such an area. Only a few hundred tourists, nearly all local French residents, visited the park last year; open-cast iron ore mining would provide a very large economic return for a short period, cattle herding rather less so. Both would very quickly destroy the area. In the long run controlled tourism, with some of the profits ploughed back into the park, would provide the greatest economic return, and for this Niger's relative proximity to Europe is an advantage. Some senior government officers know this, but without advice and financial help they can do nothing.

\section{Conclusions}

Niger, in common with many of its neighbours in North and West Africa has four basic problems:

(a) Severe soil erosion caused by low annual rainfall for several years, partly perpetuated by overgrazing and tree destruction;

(b) Shortage of natural resources and food;

(c) Lack of technically trained personnel and a low educational level;

(d) Rapid population increase.

The state of the wildlife reflects the severity of these problems. Recently, conditions have become even worse. In the arid areas, the large mammal populations have been reduced to very low levels in the last five years, and it is doubtful that the addax or scimitarhorned oryx will survive another five. There is more hope further south if the right facilities can be provided quickly at the Parc du W. A well run hotel and tourist service, combined with efficient game management, would almost certainly ensure the park's survival. Once established this would provide a working example and a sound economic reason for preserving the other wild areas which are under pressure in Niger.

\section{Acknowledgments}

The author would like to thank the British Council and the Brooke Hospital for generously supporting this visit financially, and Barry and Sandra Humphrey who suggested it and made all the internal arrangements.

The author is the resident Veterinary Officer of the Zoological Society's collection at Whipsnade Park. 